\title{
A Longitudinal-Bending Hybrid Linear Ultrasonic Motor and Its Driving Characteristic
}

\author{
Huajie Qu, Chendong Liu, Lei Zhang, Jianjun Qu (D), and Baoyu Song \\ Tribology and Piezoelectric Drive Technology Laboratory, School of Mechatronic Engineering, Harbin Institute of Technology, \\ Harbin 150001, China \\ Correspondence should be addressed to Jianjun Qu; qujianjun@hit.edu.cn
}

Received 12 October 2021; Accepted 23 December 2021; Published 6 January 2022

Academic Editor: Jiaxi Zhou

Copyright (c) 2022 Huajie Qu et al. This is an open access article distributed under the Creative Commons Attribution License, which permits unrestricted use, distribution, and reproduction in any medium, provided the original work is properly cited.

As a new type of driver, linear ultrasonic motor (LUSM) is widely used in the high-tech field because of its low speed, high thrust, low noise, and no electromagnetic interference. However, as an actuator used in microdevices, most of the existing LUSMs are large in size and not compact in structure. In order to overcome these limitations, a new structure of linear ultrasonic motor's stator is developed in this paper. The stator is similar to a tuning fork structure, which is divided into three parts: two driving feet, two driving legs, and the driving body. By using the first-order longitudinal vibration mode of the whole stator and the unique partial second-order bending vibration mode of the driving legs to achieve vibration mode degeneracy, a mode hybrid linear ultrasonic motor that is easy to miniaturize is proposed. Its working principle is analyzed. The dynamic analysis of the stator is carried out by using finite element software. The structure dimension of the stator and the driving frequency under the working mode are determined. At the same time, the feasibility of driving feet synthesizing elliptical motion is verified theoretically and experimentally. In addition, the LUSM test setup is built. The effects of driving frequency and $V_{\mathrm{pp}}$ on stator stall force and average velocity are studied. The results show that the maximum stall force can reach $99 \mathrm{mN}$, and the average velocity of the motor is $88.67 \mathrm{~mm} / \mathrm{s}$ with $V_{\mathrm{pp}}=320 \mathrm{~V}$ and driving frequency $80.2 \mathrm{kHz}$. The proposed LUSM is appropriate for use in occasions with quick return characteristics, like the controlling valve or nozzle of the printer. The research results provide guidance for the stator design of the linear ultrasonic motor.

\section{Introduction}

As a new type of actuator, the ultrasonic motor has a promising future in the fields of minimally invasive medicine, image acquisition, and mobile devices. Canon was the first to apply hollow annular traveling wave ultrasonic motor [1] and bar-type ultrasonic motor [2] in lens focusing system. With the development of mobile devices, the performance of the camera system is increasingly improved, which requires not only a high-precision driver but also a small size. In mobile devices, the most commonly used lens focusing actuator is the voice coil motor [3]. With the change of lens material and the improvement of adjustment requirements, the driving force of the voice coil motor gradually cannot meet the requirements, and an actuator with higher energy density is urgently needed. Linear ultrasonic motor (LUSM) has the characteristics of large driving force, small size, and high precision. It is expected to be applied to the microprecision driving system of mobile devices such as mobile phones, instead of the electromagnetic motor, which has aroused great research interest.

The standing wave linear motor has the advantage of a flexible structure. The stator of the earliest standing wave LUSM is rod or column shape, which is composed of a Langevin transducer [4-6]. Although these motors have large thrust, most of them are large in size, complex in structure, and heavy in weight and are not easy to miniaturize. The other is the LUSM, whose stator structure is plate or frame, and its structure is compact and convenient for miniaturization. This type of motor is divided into singlemode type and hybrid mode type. The former has a single modal [7-11] without stator modal degeneracy problems. These structure designs are simple and are easy to miniaturize, and the single-phase electrical signal can be used to 
drive. However, this kind of motor often has no common nodes leading to difficulties with stator fixation. In order to realize the reciprocating motion, different vibration modes of the same vibration mode [7] or different modes [8, 9] are often adopted. The driving frequency of reciprocating motion is quite different, which brings some difficulties to the design and control of the driving circuit. In recent years, LUSM with the hybrid mode has been studied more. The driving foot track of this kind of motor is superimposed by two modes with the same frequency and different modes of vibration, which can be divided into longitude-bend hybrid $[12,13]$, bending-bend hybrid [14-16], and other hybrids. The in-plane longitudinal-bending LUSM has the advantage of thin thickness and is one of the most research hotspots in recent years. Zumeris et al. [12] first proposed the longitudinal-bending LUSM. They made use of the firstorder longitudinal vibration and the second-order bending vibration of the rectangular plate and designed a driving foot for elliptical vibration on the width side of the rectangular plate to drive the linear motion of the actuator. Later, Takano et al. [17], Shi and Zhao [18], Wan and Hu [19], and Wang et al. [20] also designed single-drive foot longitudinal-bending hybrid LUSMs with different structures, respectively, with a maximum thrust of $3.2 \mathrm{~N}$ [18]. However, such motors only generate thrust force on one side of the stator. The vibrational energy, on the other side, is not being used efficiently. In order to improve the thrust output, scholars designed longitudinal and bending hybrid LUSMs driven by multiple legs [13, 21-23]. Among them, the stator of the LUSM of Shi et al. [21] and Yang et al. [22] has two driving feet, but only one driving foot contacts the actuator each time in the operation of the motor, and the problem of large stator size still exists. Recently, Tian et al. [13] and Tanoue and Morita [23], respectively, proposed hybrid mode LUSMs with four-drive feet. The stator size in literature [23] is $20 \mathrm{~mm}$ along the motion direction, and the driving force can reach $294 \mathrm{mN}$, but the stator thickness direction is large. Tian et al. [13] adopted a combination structure of multiple stators, resulting in a complex stator structure with a large size. The development of micro- and small linear ultrasonic motors is an urgent demand for mobile equipment. The hybrid mode LUSM has the advantages of a simple driving circuit and convenient control, which has become a research hot topic in recent years. Shunsuke and Tomoaki [24] made many exploratory studies on microlinear ultrasonic motors driven by the same frequency and proposed a thin square hollow out-ofplane vibration hybrid mode $\operatorname{LUSM}[25,26]$, which is expected to be used in mobile phone microcamera shots, whereas the stator fixation and actuator preloading of the motor are somewhat complicated. It can be seen that many studies have been done on the miniaturization of LUSM, but there are still some problems such as stator fixation difficulty and actuator preload. In addition, making full use of the vibration energy of the stator to achieve a large thrust-to-weight ratio is also the research direction of microminiature LUSM.

This paper proposes a hybrid vibration modal of a linear ultrasonic motor using in-plane stator vibration, which is easy to microminiaturize. The stator structure is similar to a tuning fork with symmetrical distribution of two driving feet. These driving feet can contact the slider to produce driving action at the same time. This special structure makes the first-order longitudinal vibration mode of the whole stator and the second-order bending vibration mode of the partial driving legs degenerate. In order to obtain effective drive at the same frequency, degeneracy conditions of frequency and mode of two vibration modes are studied. The linear ultrasonic motor prototype is developed, and the performances of the motor are preliminarily evaluated.

\section{Structure and Working Principle of LUSM}

The structure of the linear ultrasonic motor (LUSM) is shown in Figure 1. As shown in Figure 1(a), the LUSM is mainly composed of a stator, sliders, and spring preloading device. The stator is a thin metal plate similar to the tuning fork's shape, as shown in Figure 1(b). Its structure is divided into three parts. In area 1 , there is a pair of driving feet that drive the sliders. Area 2 contains a pair of driving legs that are symmetrically pasted with two long piezoceramics (P1 and P3). Area 3 is the stator's body with two piezoceramics (P2 and P4) pasted on both sides separately. The sliders of the motor are two symmetrical L-shaped boards contacting both driving feet at the same time through the spring preloading device.

The stator structure determines the existence of inplane longitudinal vibration and bending vibration. For the stator proposed in this paper, the working modes are selected as in-plane partial second-order bending vibration mode of driving legs and global first-order longitudinal vibration mode. In order to form the elliptical motion of the particle at the driving feet, two conditions need to be satisfied: (a) the frequencies of two vibration modes need to be very close. (b) Two vibration modes form nearly orthogonal vibration displacement on the driving feet. Under the partial second-order bending vibration mode, there is almost no vibration displacement on the stator's body. Two driving legs bend symmetrically and vibrate at driving feet's arc in the direction as shown in Figure 2(a). In the global first-order longitudinal vibration mode, there is a nodal plane without vibration displacement in the middle part of the stator. The stator's body and driving legs contact and extend to the middle part at the same time, forming a vibration at the arc position of the driving feet, which is shown in Figure 2(b). Therefore, two spatial nearly orthogonal vibrations are formed at the circular position of the stator's driving feet. Using piezoceramics to stimulate stator vibration, the polarization direction, deformation direction, and electric field direction of piezoceramics on the stator are shown in Figure 3(a). Four piezoceramics have the same polarization mode, and the vibration mode is $d_{31}$. P1, P2, and P3, P4, divided into A and B phases, are pasted on both sides of the stator elastomer according to the polarization mode, respectively. P1 and P3 are partial second-order bending vibrations excited by one phase, while P2 and P4 are overall first-order longitudinal 


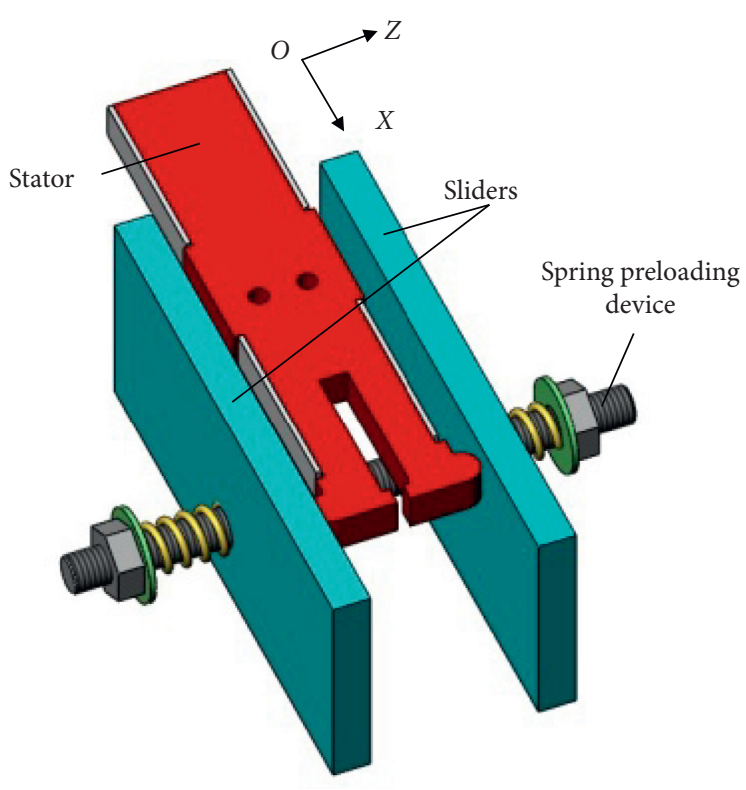

(a)

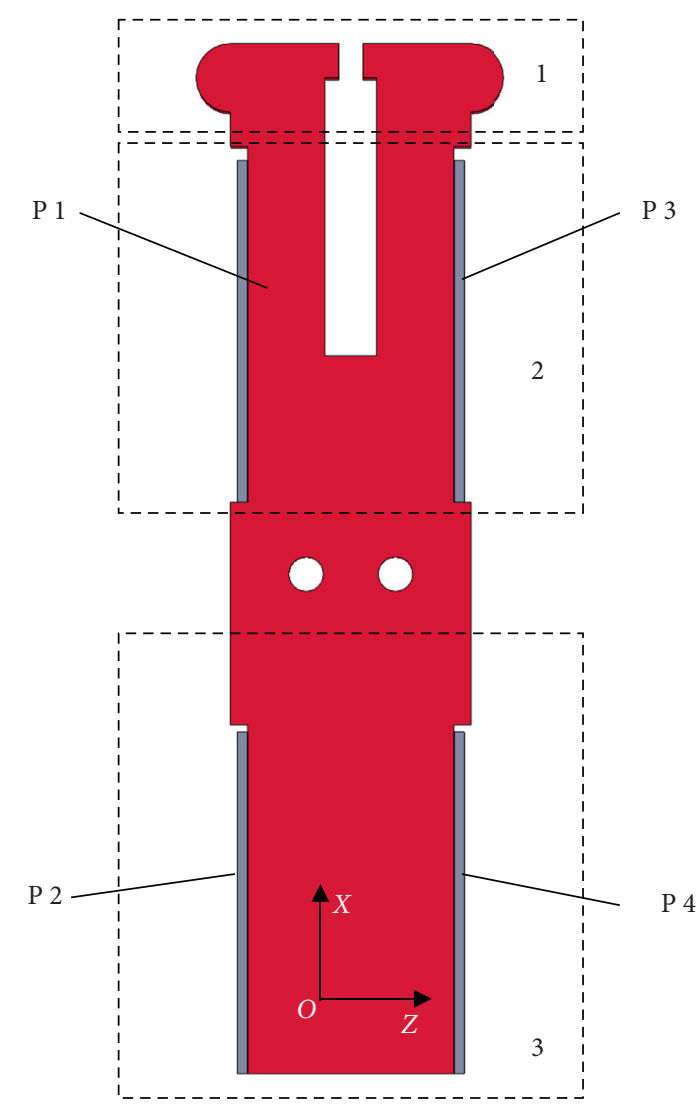

(b)

Figure 1: Structure diagram of LUSM. (a) 3D structure of LUSM. (b) Stator of LUSM.

vibrations excited by another phase. When the sinusoidal AC voltage signal is applied in the polarization direction, the piezoceramics expand and contract in the $x$-axis stimulating the stator elastomer's resonance to produce deformation. The stator elastomer is grounded. As the voltage exciting mode applied to four piezoceramics is shown in Figure 3(b), the excitation voltages $U_{A}$ and $U_{B}$ are as follows:

$$
\begin{aligned}
& U_{A}=A_{E} \sin (2 \pi f t), \\
& U_{B}=A_{E} \sin \left(\frac{2 \pi f t+\pi}{2}\right) .
\end{aligned}
$$

$A_{E}$ is the amplitude of the excitation voltage, and $f$ is the frequency of the excitation voltage. The partial second-order bending vibration and the global first-order longitudinal vibration of the driving legs can degenerate. By using the excitation signal in the equation, those two working modes can be excited simultaneously on the driving feet. The elliptical vibration with opposite rotation direction can be synthesized, respectively, at the arc positions of two driving feet, so as to realize the movement of the slider in one direction. If changing the phase of two sinusoidal voltage signals, the elliptical vibration of driving feet can be reversed, so that the sliders reverse. Figure 4 shows the combination process of stator elliptic motion in a period according to the excitation mode in Figure 3.

\section{Design Principle}

3.1. Modal Degeneracy. In order to form the in-plane elliptic motion of the stator driving feet particle, the same frequency resonance of the two modes is needed. And it is necessary to degenerate the first-order longitudinal vibration mode, and the partial second-order bending vibration mode of the driving legs needs to degenerate. Therefore, it is necessary to obtain two vibration modes with very similar frequency values and vibration modes in line with the requirements of the working principle. The finite element method can be used to analyze the modal of the stator and obtain the stator vibration mode and frequency. In analysis, the damping and the influence of load can be ignored; that is, the stator is considered vibrating free. According to Hamilton principle and electromechanical coupling equation of piezoceramics $[27,28]$, the modal analysis model is shown in

$$
\left[\begin{array}{cc}
M & 0 \\
0 & 0
\end{array}\right][\ddot{u} \ddot{\Phi}]+\left[\begin{array}{cc}
K & \Theta \\
\Theta^{t} & C_{p}
\end{array}\right]\left[\begin{array}{l}
u \\
\Phi
\end{array}\right]=[0],
$$

where $M$ and $K$ are mass matrix and stiffness matrix, respectively. $\Theta$ and $C_{p}$ are electromechanical coupling matrix and capacitance matrix separately. $U$ is the displacement vector of the element node. And $\Phi$ is the potential vector of the cell node. It can be seen that the natural mode of the stator structure depends on the mass matrix; that is, the mass distribution and the mass distribution depend on the 


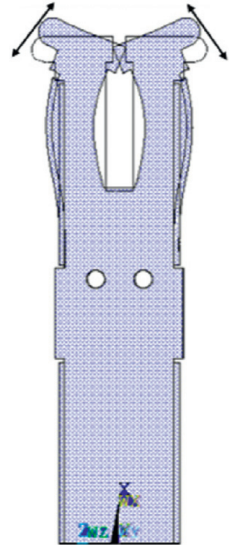

(a)

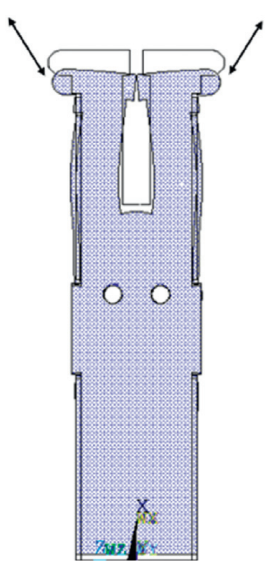

(b)

Figure 2: Operating mode of the stator. (a) Partial second-order bending vibration. (b) Global first-order longitudinal vibration.

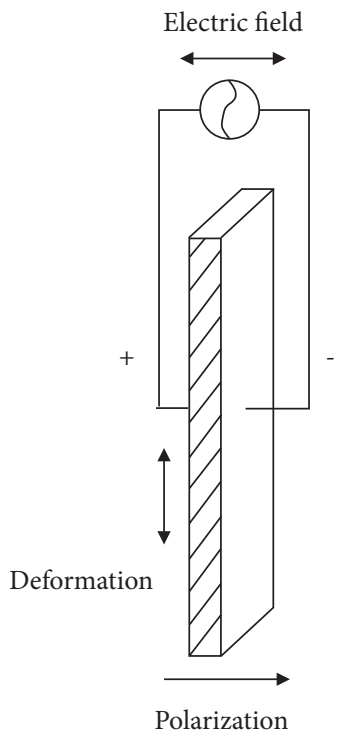

(a)

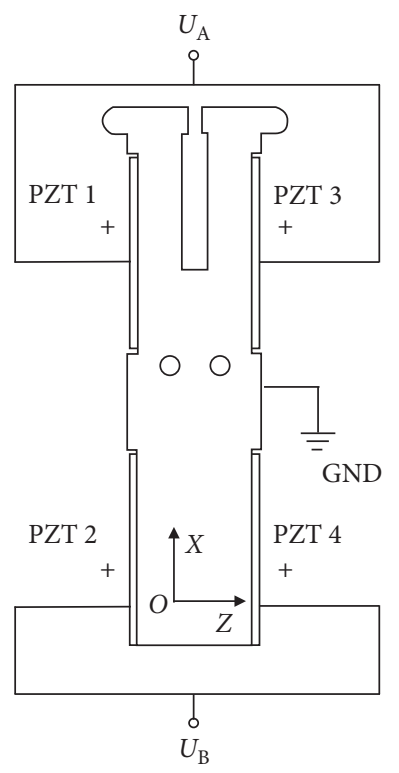

(b)

FIgURe 3: Exciting mode of the stator. (a) Polarization direction of piezoceramics. (b) The voltage exciting mode.

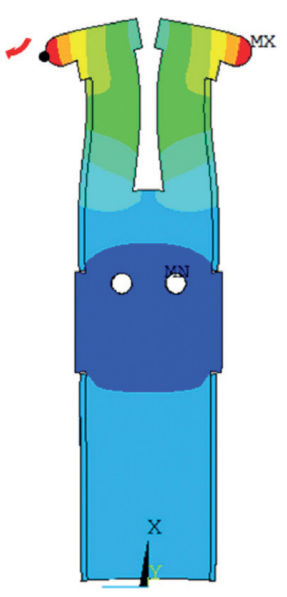

(a)

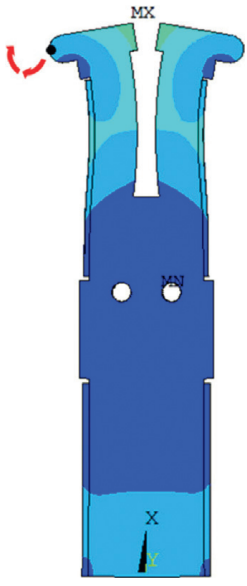

(b)

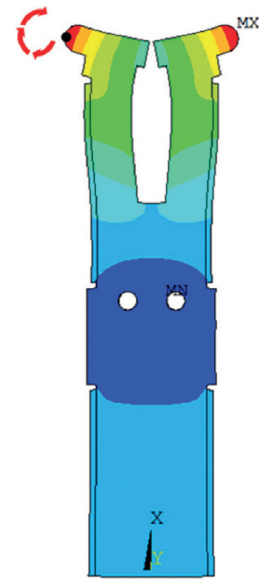

(c)

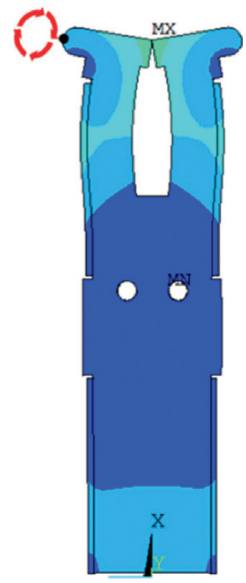

(d)

Figure 4: Combination process of stator elliptic motion. (a) $t=T / 4$. (b) $t=T / 2$. (c) $t=3 T / 4$. (d) $t=T$. 
structural size of the stator. Modal degeneracy and frequency resonance can be achieved by changing the structure size of the stator.

The main structure parameters of the stator are shown in Figure 5.

The material of stator elastomer is 7075 duralumin, and PZT- 4 is the material of piezoceramics. In this paper, 3 main structural parameters are selected to be studied: slot depth $l$, slot width $w$, and stator length of middle part $d$. By adjusting these parameters in a certain range, we can get the variation law of the global first-order longitudinal modal frequency $\left(f_{L 1}\right)$ and the partial second-order bending modal frequency $\left(f_{b 2}\right)$ of the stator with the main structural parameters, as shown in Figure 6. In Figures 6(a) and 6(b), it can be seen that $l$ and $w$ have a great influence on the frequency of partial second-order bending vibration but have little influence on the overall first-order longitudinal vibration frequency. In Figure 6(c), however, as the length $d$ in the $x$-axis increases, the partial second-order bending vibration hardly changes, while the global first-order longitudinal vibration frequency decreases significantly. According to the results in Figure 6, the two frequency curves have intersection points with the change of the main structural parameters. That is to say, by adjusting the main structural parameters, a certain structure will be found in theory where two frequencies are infinitely close or even equal, and the same frequency resonance can be realized.

By adjusting the main structural parameters, the stator structure which meets the degeneracy requirements is obtained. The structural dimension parameters of the degenerate stator are shown in Table 1. Through modal analysis, the unconstrained longitudinal and bending vibration modes of the stator are obtained, which are shown in Figure 7.

It is illustrated in Figure 7 that the natural vibration modes can meet the driving requirements and the frequency are adjacent with no constraint added. Figure 7 (a) shows the global first-order longitudinal vibration mode of the stator. The frequency is $84.59 \mathrm{kHz}$. And the middle part of the elastomer basically remains stationary. Figure $7(\mathrm{~b})$ shows the partial second-order bending mode of the driving legs. The natural frequency is $89.02 \mathrm{kHz}$. The second-order bending vibration is generated on driving feet that vibrate around the node. Due to the symmetry of the stator structure, the height of the hole can be determined according to the position of the acoustic nodes of the two modes (the point with almost no vibration displacement), and fixed constraints can be added. Figure 8 shows the modal analysis results of the stator with the fixed constraint of the hole, which shows that two vibration modes of the stator meet the driving requirements.

Among them, the global first-order longitudinal frequency is $89.25 \mathrm{kHz}$, and the partial second-order bending frequency is $89.66 \mathrm{kHz}$. The difference between those two frequencies above is only $0.41 \mathrm{kHz}$. The frequency of bending vibration only changes by $0.64 \mathrm{kHz}$, while the longitudinal vibration's frequency changes greatly after applying the restraint. This analysis indicates that the bending vibration of the stator is actually the bending vibration of the driving leg (the partial vibration of the stator). The stator body is the fixed part of the stator, and the constraint hardly affects the bending vibration of the driving legs, which is also the advantage of the symmetrical stator structure in this paper.

3.2. Harmonic Response Analysis. In order to obtain the vibration amplitude of longitudinal vibration and bending vibration of the particle on the stator driving feet at different frequencies, the harmonic response of the stator is analyzed by the finite element method. Due to the finite element model obtained in Section 3.1, two holes are fixed in $X Y Z$ direction according to the excitation mode in Figure 3. Two sinusoidal AV voltages with a phase difference of $90^{\circ}$ and peak-to-peak voltage $\left(V_{\mathrm{pp}}\right)$ of $300 \mathrm{~V}\left(U_{\mathrm{A}}\right.$ and $\left.U_{\mathrm{B}}\right)$ are applied to two pairs of piezoceramics, respectively. Set the driving frequency range from $80 \mathrm{kHz}$ to $100 \mathrm{kHz}$. The observation point $Q$ is selected as the highest point in the $z$-axis of the driving foot arc in Figure 9(a), which is also the point on the contact interface between the driving feet and the slider. The amplitude-frequency curve on $x$ - and $z$-axes is shown in Figure 9(b).

It can be seen from Figure 9 that the frequency difference corresponding to the highest amplitude resonance point in $x$-axis and $z$-axis is less than $0.2 \mathrm{kHz}$. When the resonance frequency is $87.1 \mathrm{kHz}$, the $x$-axis vibration displacement is the largest, which is $1.98 \mu \mathrm{m}$. Besides, the $z$-axis vibration displacement component is the largest, which is $0.54 \mu \mathrm{m}$ at $86.95 \mathrm{kHz}$. Through the harmonic response analysis, the driving principle of the stator is verified, which provides a reference range of driving frequency for the actual driving of the linear ultrasonic motor.

3.3. Transient Analysis. The transient analysis of the particle on the surface of the driving foot can get the trajectory of the particle changing with time and understand the process and time of the stator from vibration to vibration stability, which can provide theoretical guidance for the high-precision drive control of the motor in the future. In the transient dynamic analysis, it is necessary to apply voltage load varying with time on the outer surface of four piezoceramics. In order to facilitate the loading of the voltage signal, the surface of piezoceramics in the finite element model is coupled by nodes. The two phases of A and B are, respectively, applied with a frequency of $87 \mathrm{kHz}$. The phase difference and applied peak-to-peak voltage are consistent with the harmonic response analysis settings. The variation of the amplitude of a particle on the driving foot surface with time on $x$ - and $z$ axes is obtained in Figure 10. It can be found out that the stator needs a transient process from starting to vibration stabilization, which is about $0.35 \mathrm{~ms}$. Figure 11 shows the vibration trajectory of the driving foot's arc particle in $X-Z$ plane under a steady state, which is exactly an elliptical track.

3.4. Stator Prototype and Driving Frequency Test. The stator prototype is shown in Figure 12. The size of the piezoceramics pieces is $10 \times 2 \times 0.3 \mathrm{~mm}^{3}$ pasting, respectively, on both sides of the stator body and the driving legs by epoxy glue. The conducting wire is bonded on the positive 


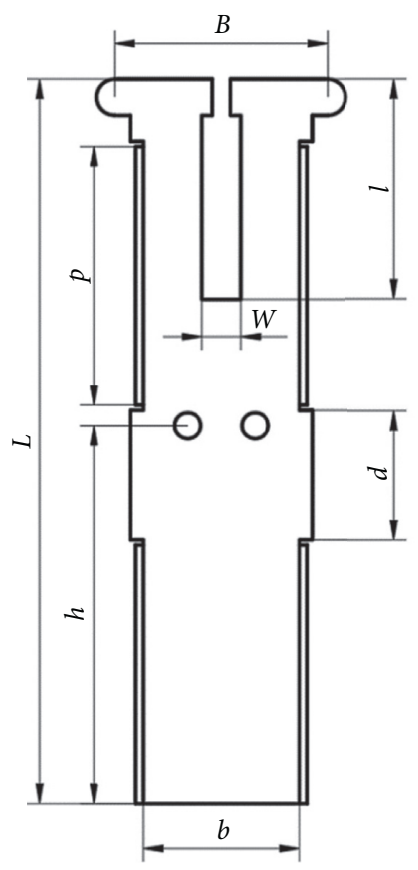

(a)
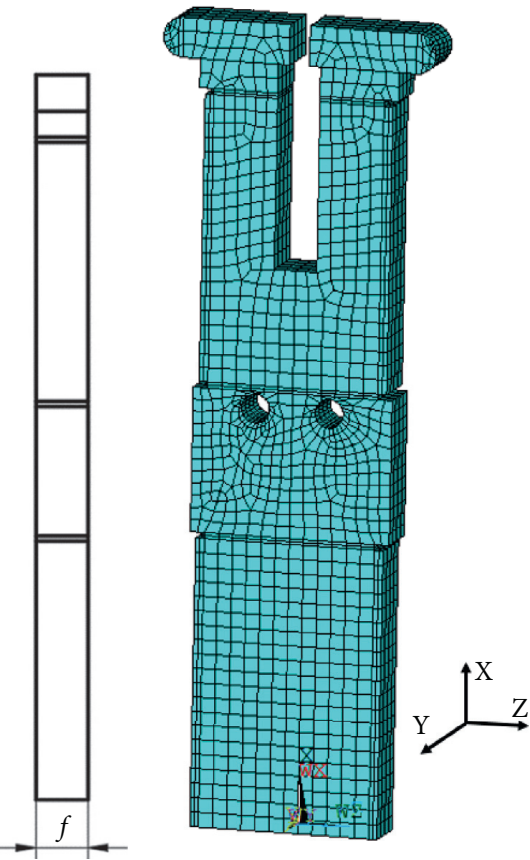

(b)

Figure 5: Main structure parameters and FE model of the stator. (a) Main structure parameters. (b) FE model.

electrode of the piezoceramics through soldering tin and conductive resin.

In order to verify the driving frequency and effect of the stator designed, a simple and effective method is adopted. A small bearing is used to contact the particle of the stator driving feet, and the driving effect is judged according to the rotation of the small bearing. In the test, the driving frequency is generated from the signal generator. As the appropriate driving frequency is found, the two driving feet can produce symmetrical elliptical motion. The formation of elliptical motion is verified by observing whether the small bearing is driven to rotate after friction that is generated at the highest contact point between the small bearing and the driving foot arc. Thus, the driving frequency of the stator is determined. Set the peak-to-peak voltage to $300 \mathrm{~V}$ and the sweep frequency range of the signal generator from $75 \mathrm{kHz}$ to $95 \mathrm{kHz}$ (increasing from $0.2 \mathrm{kHz}-1 \mathrm{kHz}$ ). The test principle of stator driving feasibility is shown in Figure 13.

Place the small bearing at the highest point of the driving foot arc. The small bearings on both sides can rotate symmetrically as the driving frequency varies from $79 \mathrm{kHz}$ to $80.5 \mathrm{kHz}$. At $80.2 \mathrm{kHz}$, the rotation velocity of the small bearing is the fastest. Adjust the phase difference to $\pm 90^{\circ}$, and the small bearing can rotate forward and backward. It shows that the elliptical motion is formed on the lateral side of the driving foot, and the reversing can be realized by adjusting the phase difference. Compared with the resonant frequency of harmonic response analysis, there is a certain difference between the excitation frequency of the fastest rotating speed of bearings and the resonant frequency in the simulation analysis with an error of $7.92 \%$.
The causes of the error may be as follows:

(1) Machining dimension error: it can be seen that the stator structure size is small, and the size change of $0.1 \mathrm{~mm}$ will affect the modal analysis results. Wireelectrode cutting is used for making the stator. After the processing, the stator is rough and needs to be polished, which changes its dimension. Therefore, the error produced in the process of machining may make the structure size of the stator change slightly, thus affecting the frequency of the working mode.

(2) The error of fixed constraint difference in simulation and experiment: in the simulation, the stator's fixed constraint mode is all DOF constraint; that is, the inner walls of two holes of the stator are constrained in XYZ three directions. This constraint mode cannot fully reflect the constraint in the actual experiment.

\section{Performance Evaluation}

4.1. Prototype of LUSM. In order to evaluate the performance of linear ultrasonic motor, a linear ultrasonic motor test setup is built in this paper. The reciprocation control and experimental setup of LUSM are shown in Figure 14.

The controller can realize the reciprocating motion of the slider through the switching circuit. As the slider moves to both sides' limit positions of the motor, the contact switch turns on. The controller gets the signal and accumulates the number of reciprocating motion $n$ through the counter. Use a timer to record the running time $T_{n}$ of the slider. And the effective single stroke's length of the slider $S$ equals $32 \mathrm{~mm}$. 


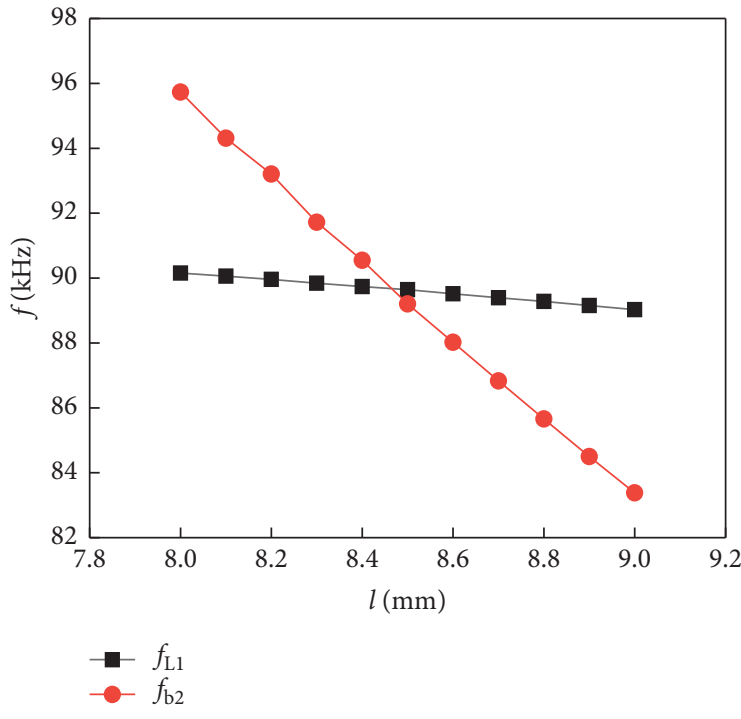

(a)

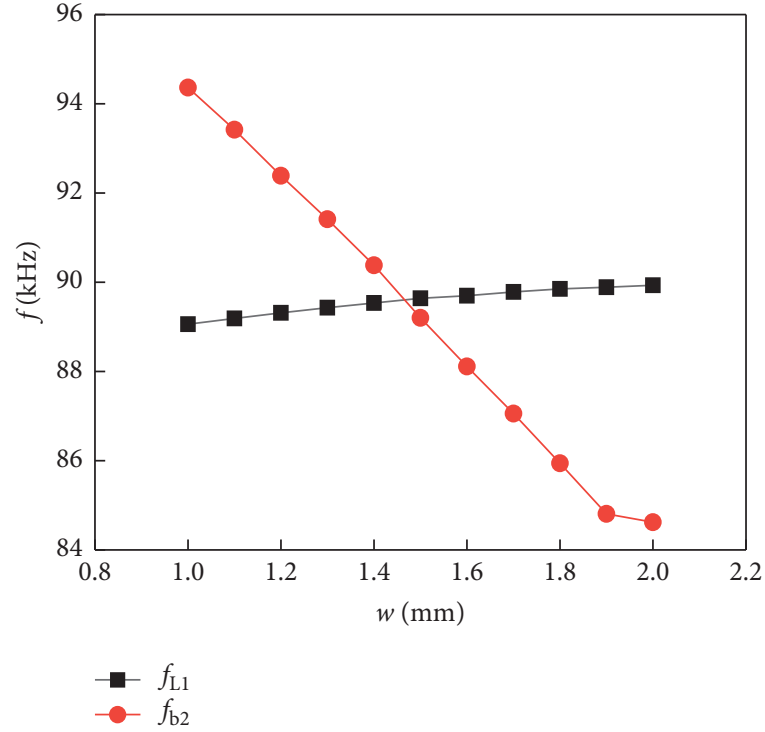

(b)

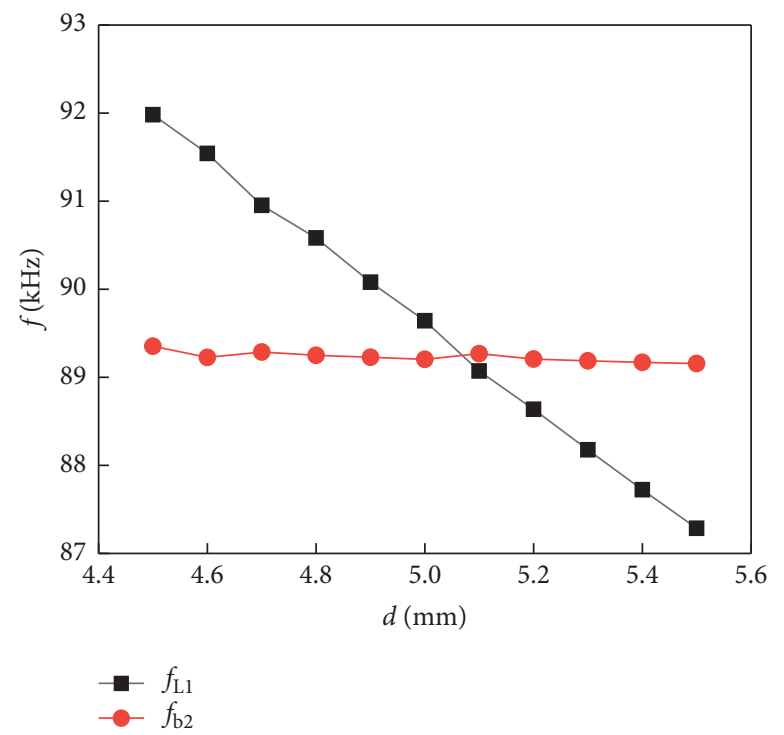

(c)

FIGURE 6: Variation of modal frequencies with main structural parameters of the stator. (a) Slot depth $l$. (b) Slot width $w$. (c) Stator length of the middle part $d$.

TABle 1: Structural dimension parameters of degenerate stator.

\begin{tabular}{lccccccccc}
\hline Parameters & $L$ & $l$ & $B$ & $b$ & $d$ & $w$ & $p$ & $t$ & $h$ \\
\hline Value $(\mathrm{mm})$ & 28 & 8.5 & 8.2 & 6 & 5 & 1.5 & 10 & 2 & 14.6
\end{tabular}

The average velocity $v$ of the LUSM can be expressed in

$$
v=\frac{n \times S}{T_{n}} .
$$

This is equipped with a force sensor on the right side of the setup, which can be moved back and forth. When it is necessary to measure the stall force, the force sensor will be placed close to the limit block of the slider base. As the slider moves to the right, the rod of the force sensor will be pressed to measure the stall force of the motor. If not measuring the stall force, the force sensor will be moved far from the limit block, which will not influence the reciprocating of the slider. By using this setup, the effects of driving frequency and driving voltage on stall force and average velocity of motor's operation are studied.

Both stator and sliders are made of duralumin. With $V_{\mathrm{pp}}=320 \mathrm{~V}$, driving frequency $f_{\mathrm{d}}=80.2 \mathrm{kHz}$, the influence of preload $\left(F_{\mathrm{c}}\right)$ on stall force $\left(F_{\mathrm{d}}\right)$ and no-load velocity $(v)$ is studied. The test results are shown in Figure 15. It can be seen that as the preload changes from $0.5 \mathrm{~N}$ to $1.5 \mathrm{~N}$, both the noload velocity and the stall force increase first and then decrease with the increase of preload. The difference is that the no-load velocity and the stall force cannot reach the maximum value under the same preload. Considering that the proposed LUSM has a high demand for driving force, as $F_{\mathrm{c}}$ is $1.1 \mathrm{~N}$, stall force 


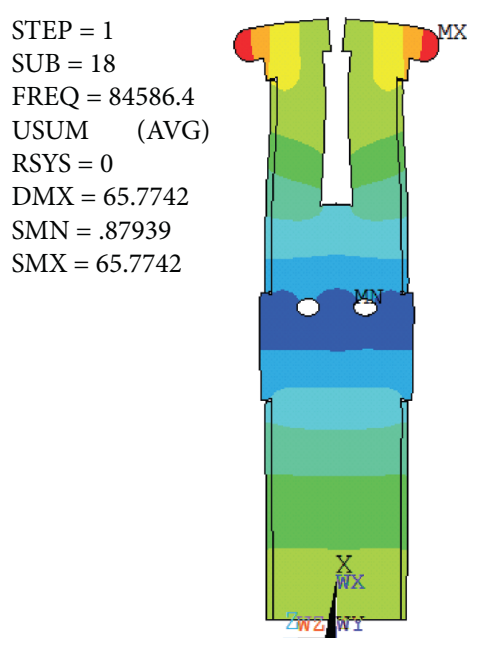

(a)

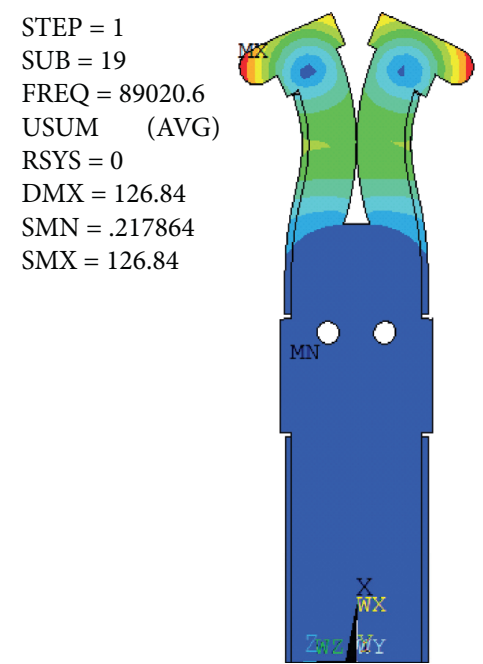

(b)

FIGURE 7: Unconstrained stator mode. (a) Global first-order longitudinal vibration mode. (b) Partial second-order bending vibration mode.

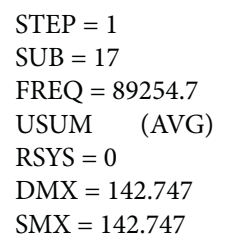

$\mathrm{SMX}=142.747$

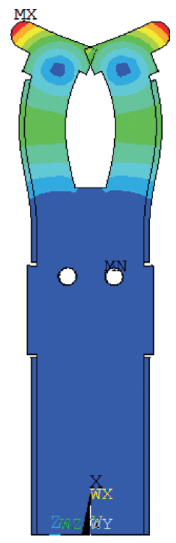

(a)
STEP $=1$

$\mathrm{SUB}=18$

FREQ $=89657.9$

USUM (AVG)

RSYS $=0$

$\mathrm{DMX}=75.8471$

SMX $=75.8471$

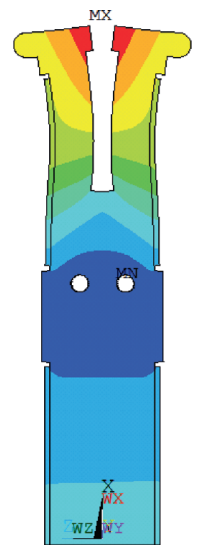

(b)

Figure 8: Modes of stator with all DOF. (a) Partial second-order bending vibration mode. (b) Global first-order longitudinal vibration mode.

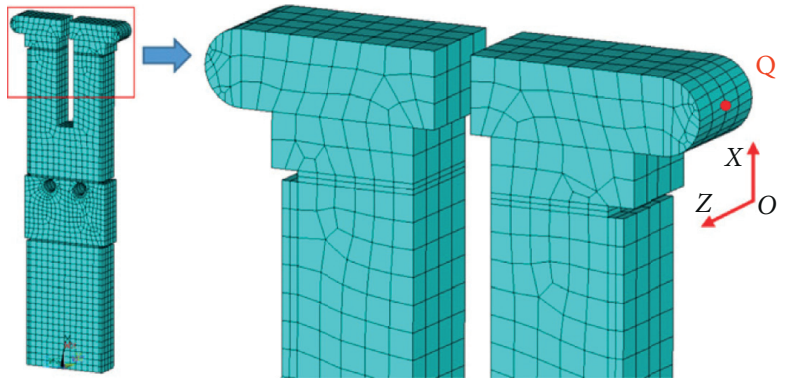

(a)

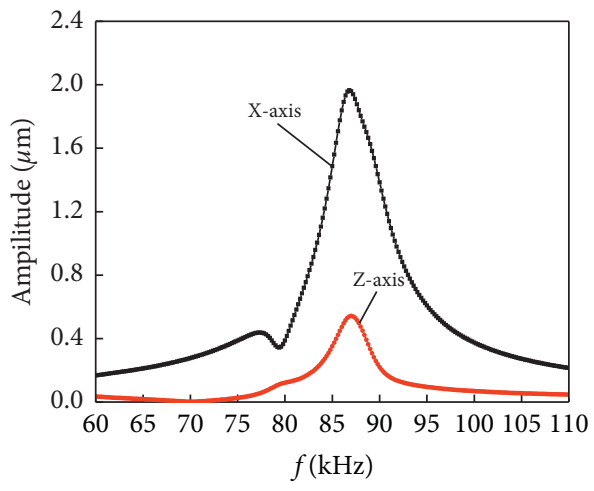

(b)

Figure 9: Amplitude-frequency curve. (a) The observation point Q. (b) Amplitude-frequency curve on $x$ - and $z$-axes. 


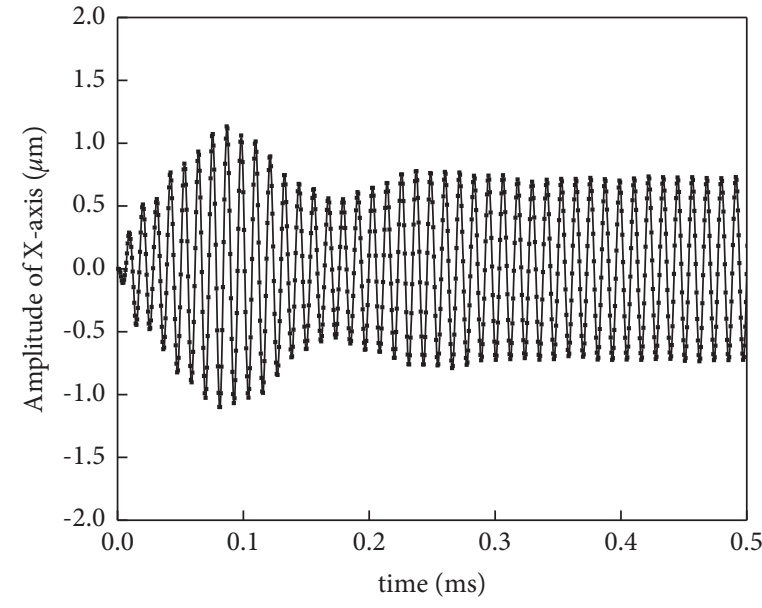

(a)

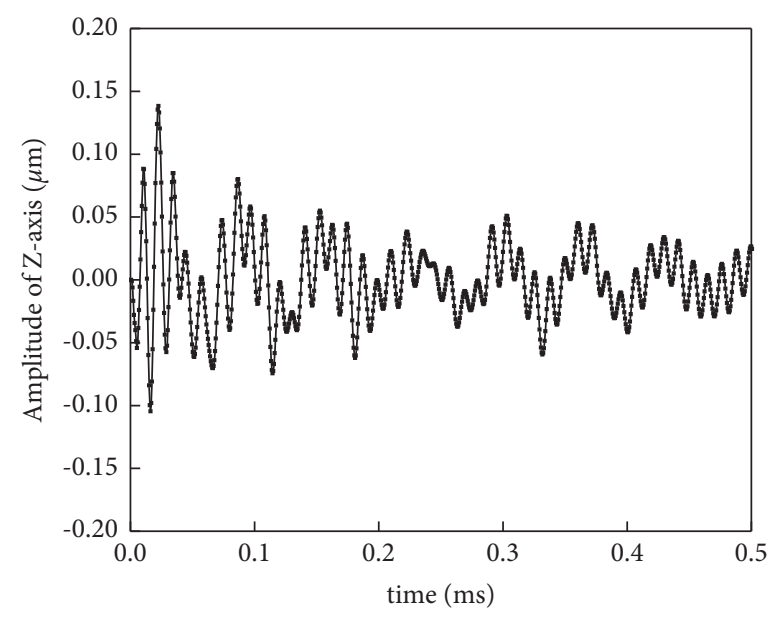

(b)

FIgURE 10: Variation of the amplitude of a particle on driving foot surface with time. (a) $x$-axis. (b) $z$-axis.

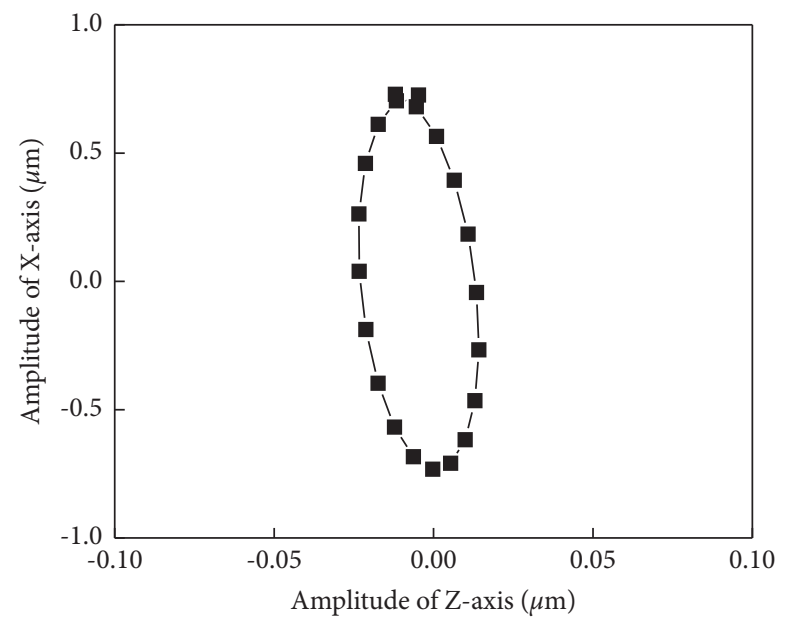

FIgURE 11: The vibration trajectory of the driving foot's arc particle in $X-Z$ plane.

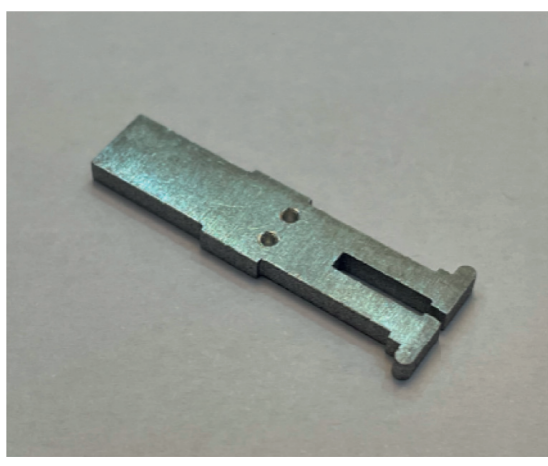

(a)

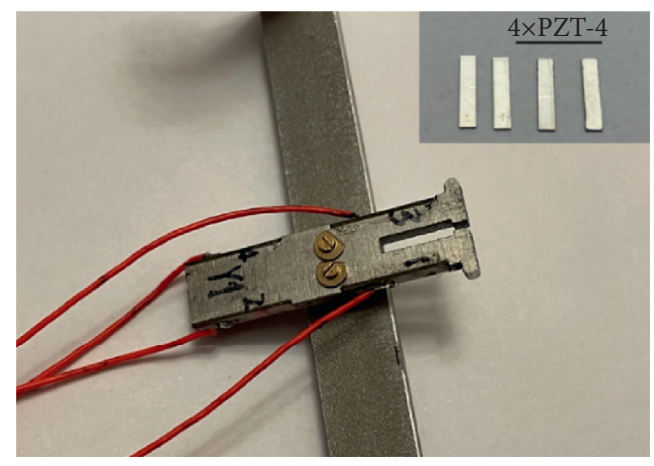

(b)

Figure 12: Prototype of the stator. (a) Stator elastomer. (b) Stator with PZT and wires. 


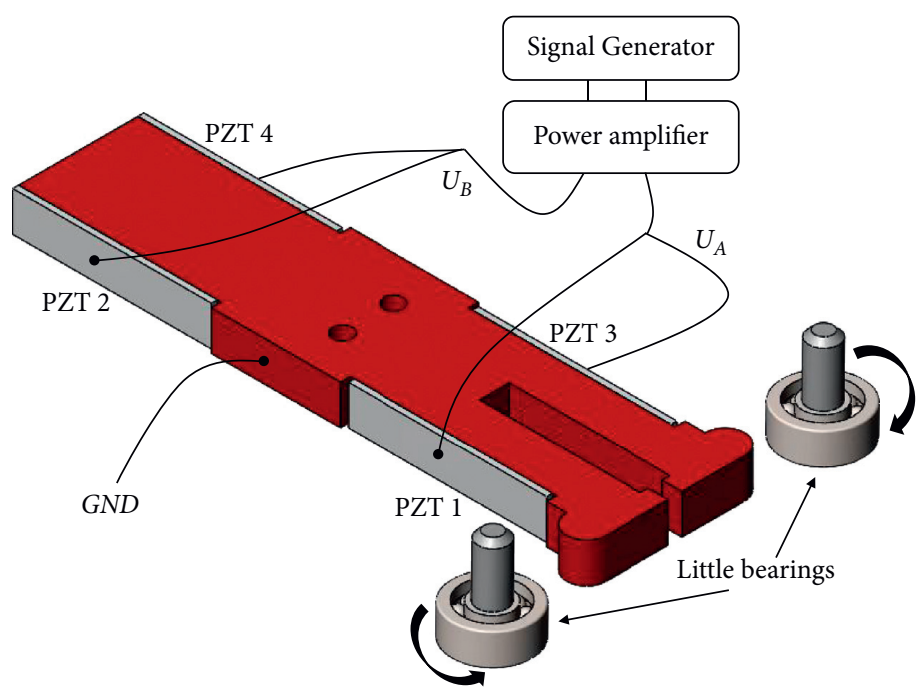

Figure 13: Test principle of stator driving feasibility.

reaches the maximum, and the no-load velocity is appropriately high. Therefore, $1.1 \mathrm{~N}$ is selected as the preload for performance evaluation of the LUSM in this paper.

\subsection{Influence of Driving Frequency on Stall Force and Average} Velocity. The preload $F_{\mathrm{c}}=1.1 \mathrm{~N}$ and $V_{\mathrm{pp}}=290 \mathrm{~V}$. By adjusting the driver, the slider can achieve smooth reciprocation with $f_{\mathrm{d}}$ from $79 \mathrm{kHz}$ to $80.5 \mathrm{kHz}$ and $90^{\circ}$ phase difference.

Within the above frequency range, seven driving frequencies are selected. The force sensor is used to measure the value of stall force, and the average value is taken for five tests.

Figure 16(a) shows the variation of stall force with driving frequencies. It can be seen that the change's trend of stall force is basically the same under the testing frequency range. Besides, the force magnitude of reciprocation is similar. The stall force of the reciprocation is the closest at $79 \mathrm{kHz}$, which indicates that the consistency of the reciprocation is the best. The maximum stall force in one direction appears at $80.2 \mathrm{kHz}$ with a $90^{\circ}$ phase difference, which is $95 \mathrm{mN}$.

Under the same driving voltage, the variation of motor velocity with $f_{\mathrm{d}}$ for every $0.1 \mathrm{kHz}$ is shown in Figure 16(a). It can be seen that, with the increase of $f_{\mathrm{d}}$, the average velocity of reciprocation first increases and then decreases. When $f_{\mathrm{d}}=80.2 \mathrm{kHz}$, the average velocity of reciprocation reaches the maximum, which is $69.4 \mathrm{~mm} / \mathrm{s}$.

4.3. Influence of $V_{p p}$ on Stall Force and Average Velocity. Figure 17 indicates the variation of stall force and average velocity under different driving voltages $\left(F_{\mathrm{c}}=1.1 \mathrm{~N}\right.$, $f_{\mathrm{d}}=80.2 \mathrm{kHz}$, and $\varphi=90^{\circ}$ ).

It can be seen that the average velocity of reciprocation rises with the increase of $V_{\mathrm{pp}}$. From $280 \mathrm{~V}$ to $290 \mathrm{~V}$, both the stall force and the velocity suddenly increase, which may be due to the instability of the experimental setup. When $V_{\mathrm{pp}}$ reaches $320 \mathrm{~V}$, the maximum stall force is $99 \mathrm{mN}$, and the average velocity of reciprocation reaches $88.67 \mathrm{~mm} / \mathrm{s}$. In the experiment, it is found that the velocity of the motor can be improved with the continuous increase of the voltage. However, the motor runs seriously hot. It means that the motor is heated, and the driving frequency drifts, resulting in the reduction of the motor speed. According to the test, when the peak-to-peak value of the driving voltage is $320 \mathrm{~V}$, the steady-state operating temperature of the motor is $45^{\circ}$ as $V_{\mathrm{pp}}=320 \mathrm{~V}$. Therefore, this driving voltage $(320 \mathrm{~V})$ is selected properly to test the load characteristics of the motor.

4.4. Study of Load Characteristic. In order to better evaluate the output performance of the prototype, the method of hanging weight is used to impose load on the slider. One end of the wire is hung with weight and bypasses the pulley. The other end is connected to the slider base. The weight of the weights is changed to impose load on the motor. The laser displacement sensor is used to measure the velocity of the slider with load. The variation of motor load characteristics and mechanical output power with the load force is shown in Figure $18 \quad\left(V_{\mathrm{pp}}=320 \mathrm{~V}, F_{\mathrm{c}}=1.1 \mathrm{~N}, f_{\mathrm{d}}=80.2 \mathrm{kHz}\right.$, and $\left.\varphi=90^{\circ}\right)$. As can be seen from Figure 18, the velocity of LUSM decreases with the increase of the load force. When the load force is $99 \mathrm{mN}$, the motor stops moving. It can also be concluded from Figure 18 that the output power increases first and then decreases with the increase in load. When the load is $70 \mathrm{mN}$, the output power of the motor is the highest, which is $4.8 \mathrm{MW}$. At this moment, the motor's running velocity is $68.27 \mathrm{~mm} / \mathrm{s}$. In the test, the voltage and current of the DC power supply that applied driving voltage to the motor were monitored at the same time. In this way, the input power $\left(P_{\text {in }}\right)$ under different load forces is calculated and added to Figure 18. It can be seen that $P_{\text {in }}$ hardly changed with the load. By calculation, the output power per unit weight of the proposed LUSM is $3.98 \mathrm{~mW} / \mathrm{g}$.

The LUSM in this paper is compared with the motor previously designed by Tanoue and Morita [23] and Tian et al. [13], and the results are shown in Table 2. 


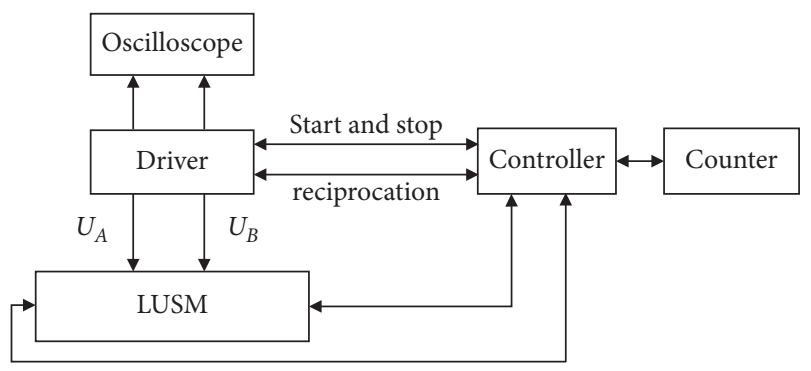

(a)

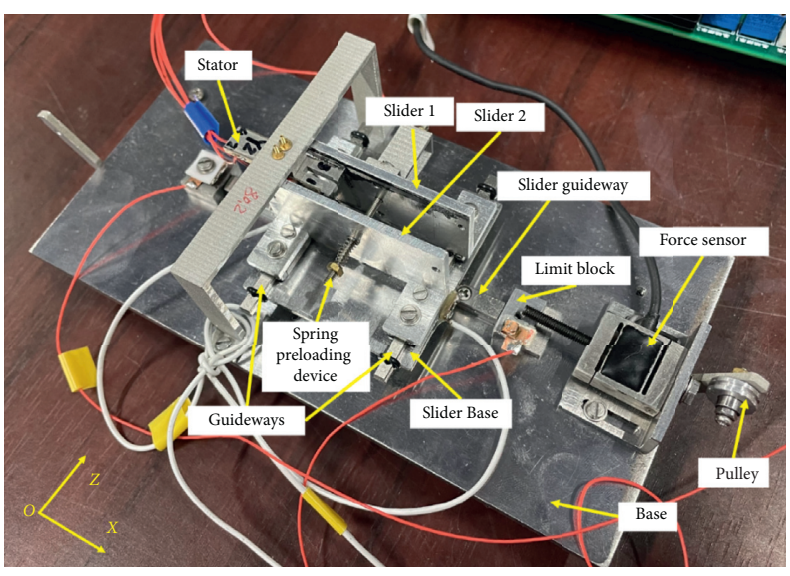

(b)

FIGURE 14: Reciprocation control and experimental setup of LUSM. (a) Control block of LUSM reciprocation. (b) Experimental setup of LUSM.

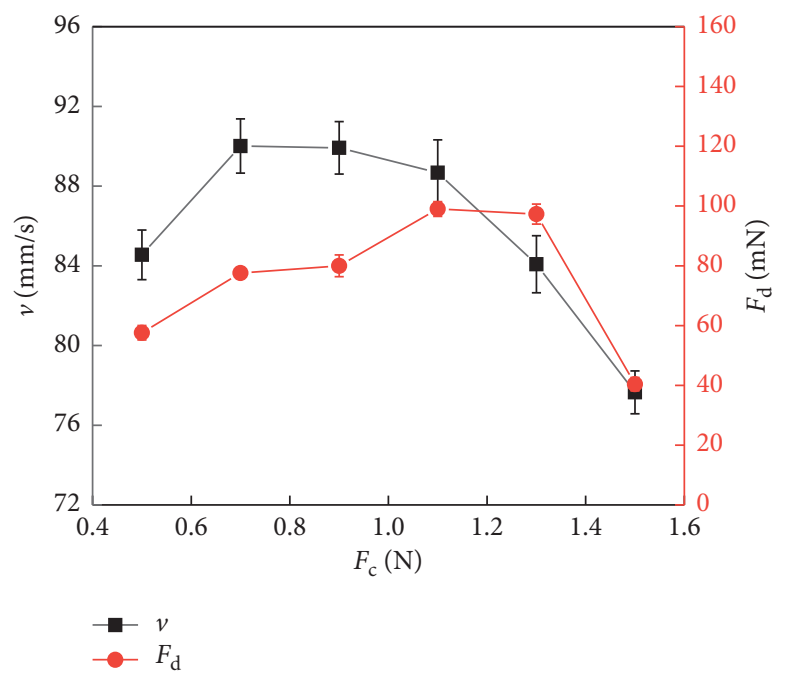

FIgURE 15: Variation of stall force and average velocity with preload $F_{\mathrm{c}}$.

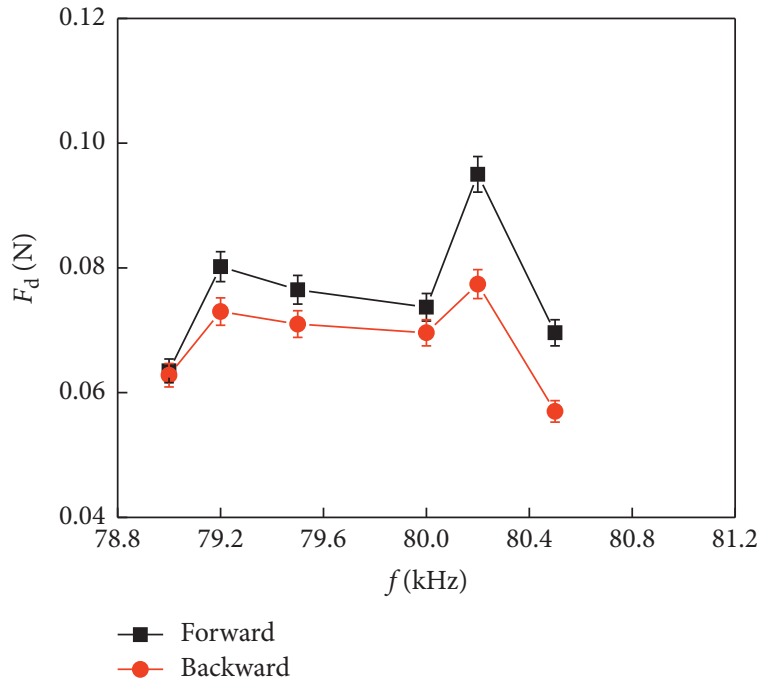

(a)

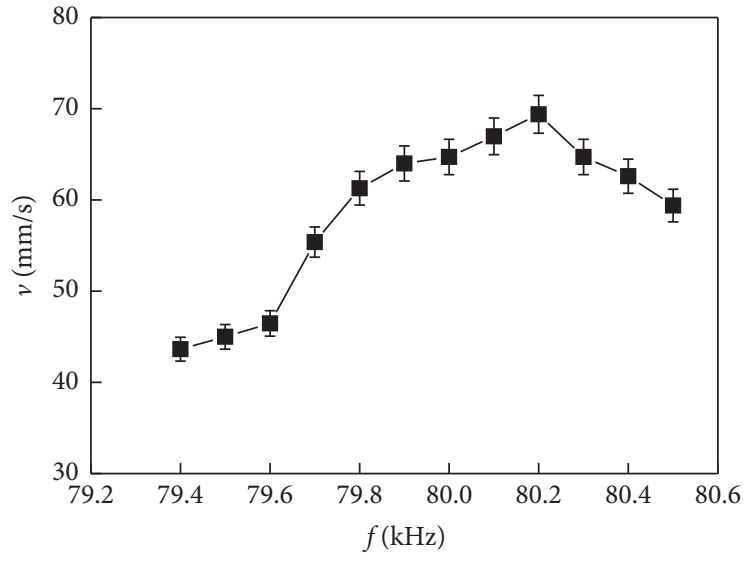

(b)

FIGURE 16: Variation of stall force and average velocity with driving frequencies. (a) Stall force-driving frequency. (b) Average velocitydriving frequency. 


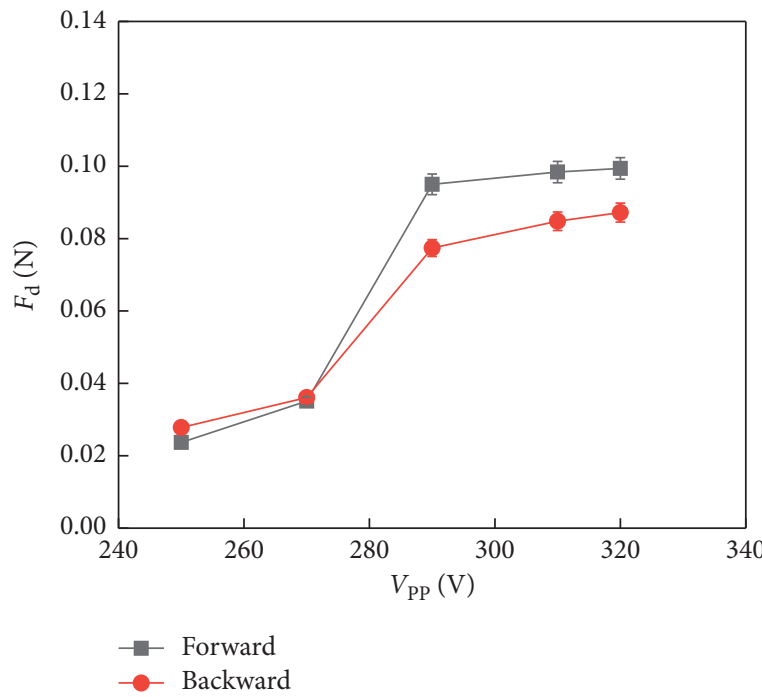

(a)

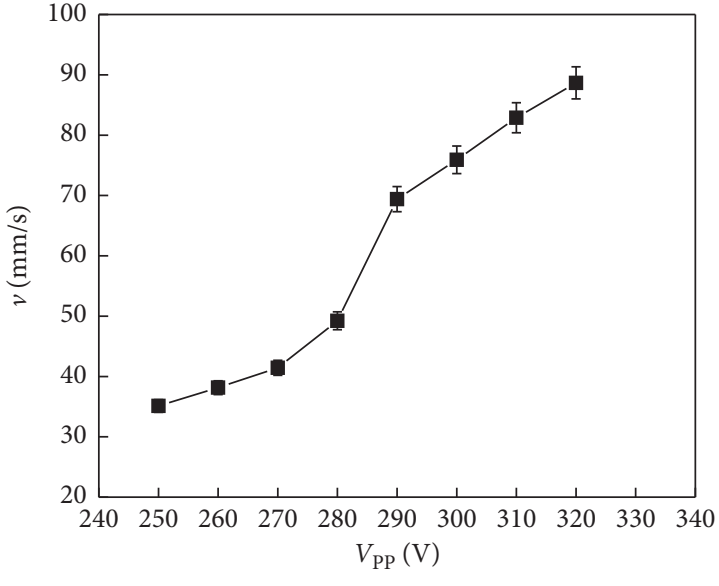

(b)

FIGURE 17: Variation of stall force and average velocity with $V_{\mathrm{pp}}$. (a) Stall force- $V_{\mathrm{pp}}$. (b) Average velocity- $V_{\mathrm{pp}}$.

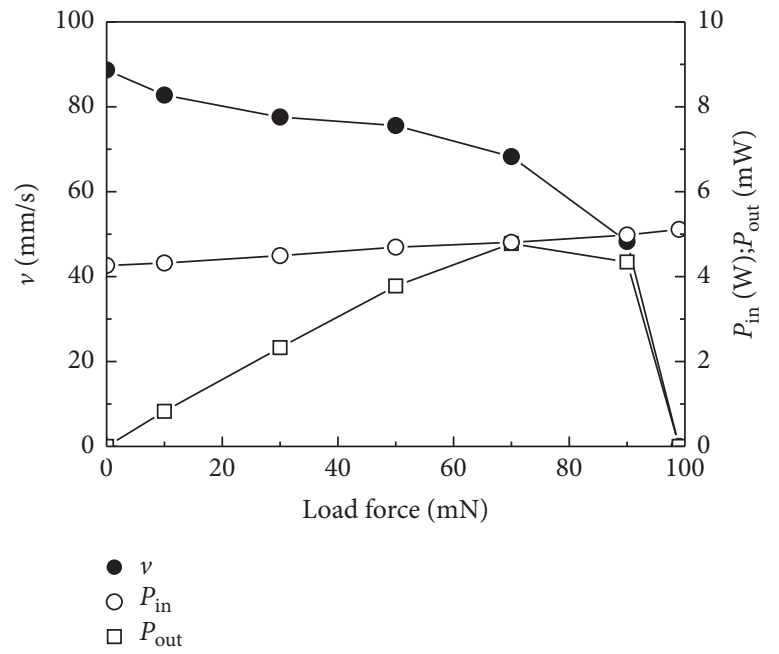

Figure 18: Variation of load characteristics with load force.

TABLE 2: Comparison between the proposed LUSM and 2 previous works.

\begin{tabular}{|c|c|c|c|}
\hline Parameters & Tian et al. [13] & Tanoue and Morita [23] & The proposed USLM \\
\hline Working frequency $(\mathrm{kHz})$ & 41.47 & 84.8 & 80.2 \\
\hline Weight of the stator $(\mathrm{g})$ & 51.6 & 5 & 1.2 \\
\hline Size of the stator (mm) & $100.6 \times 74.6 \times 7$ & $20 \times 12 \times 6.6$ & $28 \times 7 \times 2$ \\
\hline Maximum velocity $(\mathrm{mm} / \mathrm{s})$ & 1641 & 148 & 88.67 \\
\hline Maximum output power $(\mathrm{mW})$ & 225 & 23 & 4.8 \\
\hline Maximum thrust force $(\mathrm{mN})$ & 1176 & 294 & 99 \\
\hline Quantity of piezoelectrics $\left(\mathrm{mm}^{3}\right)$ & 2280 & 400 & 24 \\
\hline Thrust force per weight $(\mathrm{mN} / \mathrm{g})$ & 22.8 & 58.8 & 82.5 \\
\hline Thrust force per piezoelectrics volume $\left(\mathrm{mN} / \mathrm{mm}^{3}\right)$ & 0.52 & 0.74 & 4.13 \\
\hline Output power per weight $(\mathrm{mW} / \mathrm{g})$ & 4.36 & 4.6 & 3.98 \\
\hline
\end{tabular}

It can be seen that the weight of the stator proposed in this paper is the lightest (only $1.2 \mathrm{~g}$ ), which is $76 \%$ reduced compared with that of Morita and Tanoue. Due to the small size of the linear ultrasonic motor, the volume of the piezoelectric ceramic is also the smallest, only $24 \mathrm{~mm}^{3}$. Although the velocity and thrust force of the LUSM in this paper are smaller than those of the other two scholars, the stator's thrust force per weight in this paper can reach 
$82.5 \mathrm{mN} / \mathrm{g}$, which is $40 \%$ higher than that of the motor in literature [23] and 3.6 times that of the motor in literature [13]. In addition, the thrust force per unit piezoceramics volume can reach $4.13 \mathrm{mN} / \mathrm{mm}^{3}$, which is larger than the motor of the other two scholars. Besides, from the index of output power per weight, the motor proposed in this paper is very close to that of the other two scholars. The comparison results show that the proposed LUSM is not only simple in stator structure and small in size but also convenient in stator fixation, which has sufficient competitiveness in terms of performance. Moreover, the thickness of the stator proposed is uniform, which has obvious advantages in miniaturization. Motor's overall size can be further reduced.

\section{Conclusions}

In this paper, a mode hybrid linear ultrasonic motor is proposed. The movement direction of LUSM is consistent with the maximum dimension direction of the stator. Its stator is simple in structure and easy to process. LUSM is compact and easy to miniaturize. Through modal analysis, the structure size of the stator is determined, and the global first-order longitudinal vibration mode and the partial second-order bending vibration mode are obtained. The selection of these two vibration modes determines that the stator is easily fixed. Besides, the starting response characteristics of the stator are obtained by transient analysis. The experimental setup of the linear ultrasonic motor is built. The variation of average velocity and stall force with preload is obtained, and the optimal preload is determined to be $1.1 \mathrm{~N}$. The variation of stall force and average velocity of LUSM with $f_{\mathrm{d}}$ and driving voltage is achieved. Experimental results indicate that the motor can achieve reciprocation with $\varphi=90^{\circ}$ and $f_{\mathrm{d}}$ from $79 \mathrm{kHz}$ to $80.5 \mathrm{kHz}$. The stator's average velocity first increases and then decreases with the increase of $f_{\mathrm{d}}$. At $80.2 \mathrm{kHz}\left(V_{\mathrm{pp}}=320 \mathrm{~V}\right)$, the motor reaches the maximum velocity of $88.67 \mathrm{~mm} / \mathrm{s}$ with the largest stall forces in two directions, which are $99 \mathrm{mN}$ and $87 \mathrm{mN}$, respectively. The load characteristics of the motor are tested. The maximum output power can reach $4.8 \mathrm{~mW}$ with a load force of $70 \mathrm{mN}$.

The proposed LUSM can be mainly used in reciprocating motion occasions, especially in small size and compact structure occasions. By using the different speeds in reciprocating motion, the proposed motor is appropriate for use in occasions with quick return characteristics, like controlling valve or nozzle of the printer. In addition, the driving frequency of our motor can also be adjusted to make the reciprocating speed close to the same. Using the thin and small structure of the proposed motor, it can be applied to microprecision adjustment systems, such as lens focal length adjustment system of optical devices in mobile phones.

\section{Data Availability}

The table data used to support the findings of this study are available from the corresponding author upon request.

\section{Conflicts of Interest}

The authors declare no conflicts of interest.

\section{Acknowledgments}

This work has been supported by the National Natural Science Foundation of China (51175104).

\section{References}

[1] I. Okumura and H. Mukohjima, "A structure of ultrasonic motor for auto focus lenses," Motor Conference, vol. 11, pp. 75-85, 1987.

[2] I. Okumura, "A designing method of a bar-type ultrasonic motor for autofocus lenses," The International Symposium on Theory of Machines and Mechanics, pp. 836-841, Nagoya, Japan, 1992.

[3] J. Go and J. H. Lim, "Voice coil motor type actuator for use in camera module of mobile phone, comprises a driving coil, which is wound around the outer periphery of the carrier, and base supports the carrier, where magnet unit is arranged outside driving coil," KR2021021649-A, 2020.

[4] T. Wakai, M. K. Kurosawa, and T. Higuchi, "Transducer for an ultrasonic linear motor with flexible driving part," in Proceedings of the IEEE Ultrasonic Symposium, no. 1, pp. 683-686, Sendai, Japan, October 1998.

[5] Z. Y. Yao, D. Yang, and C. S. Zhao, "Structure design and power flow analysis of bar-structure linear ultrasonic motors," Proceedings of the CSEE, vol. 29, no. 24, pp. 56-60, 2009.

[6] X. Ying, J. P. Liu, Y. Liu, J. Yan, L. Wang, and W. Chen, “A two-DOF ultrasonic motor using a longitudinal-bending hybrid sandwich transducer," IEEE Transactions on Industrial Electronics, vol. 66, 2018.

[7] T. Kazumi, Y. Kurashina, and K. Takemura, "Ultrasonic motor with embedded preload mechanism," Sensors and Actuators A: Physical, vol. 289, pp. 44-49, 2019.

[8] J. M. Fernandez and Y. Perriard, "Optimization of a new type of ultrasonic linear motor," IEEE Transactions on Ultrasonics, Ferroelectrics, and Frequency Control, vol. 55, no. 3, pp. 659-667, 2008.

[9] M. Flueckiger, J. M. Fernandez, M. Giljum, and Y. Perriard, "Optimization of a single phase ultrasonic linear motor," in Proceedings of the IEEE Ultrasonics Symposium, pp. 23272330, New York, NY, USA, October 2007.

[10] O. Vyshnevsky, S. Kovalev, and W. Wischnewskiy, "A novel, single-mode piezoceramic plate actuator for ultrasonic linear motors," IEEE Transactions on Ultrasonics, Ferroelectrics, and Frequency Control, vol. 52, no. 11, pp. 2047-2053, 2005.

[11] H. X. Wang, Q. He, and L. Guan, "Design of ring-type standing-wave linear ultrasonic motors," Micromotors, vol. 41, no. 9, pp. 23-25, 2008.

[12] J. Zumeris, "Ceramic motor: ep," European Patent Office, Berlin, Germany, EP0755054 A2, 2000.

[13] X. Tian, Q. Quan, L. Wang, and Q. Su, “An inchworm type piezoelectric actuator working in resonant state," IEEE Access, vol. 6, p. 1, 2018.

[14] R. X. Liu, T. M. Zhang, and Y. Qin, "Research on the actuator for a linear ultrasonic motor based on in-plane bending modes," Piezoelectrics and Acoustooptics, vol. 30, no. 6, pp. 696-698, 2008.

[15] W.-H. Lee, C.-Y. Kang, D.-S. Paik, B.-K. Ju, and S.-J. Yoon, "Butterfly-shaped ultra slim piezoelectric ultrasonic linear 
motor," Sensors and Actuators A: Physical, vol. 168, no. 1, pp. 127-130, 2011.

[16] B. L. Zhang, Z. Y. Yao, and Y. Jian, "Structural design of a novel plate-shaped linear ultrasonic motor based on bending mode," Journal of Vibration and Shock, vol. 38, no. 1, pp. 118-125, 2019.

[17] M. Takano, K. Hirosaki, and M. Takimoto, "Improvements of controllability in ultrasonic linear motors using longitudinalbending multilayered transducer with independent electrodes and their applications to mirror holders," Proceedings of Symposium on Ultrasonic Electronics, vol. 31, pp. 223-224, 2010.

[18] Y. Shi and C. Zhao, "A new standing-wave-type linear ultrasonic motor based on in-plane modes," Ultrasonics, vol. 51, no. 4, pp. 397-404, 2011.

[19] Z. Wan and H. Hu, "Modeling and experimental analysis of the linear ultrasonic motor with in-plane bending and longitudinal mode," Ultrasonics, vol. 54, no. 3, pp. 921-928, 2014.

[20] X. Wang, L. Wang, and P. Yu, "Theoretical modeling and experiment studies of a bonded type longitudinal-bending hybrid linear ultrasonic motor," Proceedings of the CSEE, vol. 41, no. 14, pp. 5014-5024, 2021.

[21] Y. Shi, Y. Li, and C. Zhao, "Optimum design of a linear ultrasonic motor based on in-plane modes," Proceedings of the CSEE, no. 30, pp. 56-60, 2008.

[22] X. Yang, Y. Liu, W. Chen, and J. Liu, "Miniaturization of a longitudinal-bending hybrid linear ultrasonic motor," Ceramics International, vol. 41, pp. S607-S611, 2015.

[23] Y. Tanoue and T. Morita, "Opposing preloads type ultrasonic linear motor with quadruped stator," Sensors and Actuators A: Physical, vol. 301, Article ID 111764, 2019.

[24] I. Shunsuke and M. Tomoaki, "Design and evaluation of a micro linear ultrasonic motor," Sensors \& Actuators A Physical, vol. 278, pp. 60-66, 2018.

[25] I. Shunsuke and M. Tomoaki, "Linear piezoelectric motor using a hollow rectangular stator," Sensors and Actuators A: Physical, vol. 309, Article ID 112002, 2020.

[26] I. Shunsuke and M. Tomoaki, "Design and characterization of a thin linear ultrasonic motor for miniature focus systems," Sensors and Actuators A: Physical, vol. 329, Article ID 112797, 2021.

[27] A. Henno, J. Thonas, and R. Hughes, "Finite element for piezoelectric vibration," International Journal for Numerical Methods in Engineering, vol. 2, pp. 151-157, 1970.

[28] B. Shi, M. Q. Hu, and Z. R. Zhu, "Effect of adhesive on the vibration of the stator in ultrasonic motors," Proceedings of the CSEE, vol. 21, no. 7, pp. 72-77, 2001. 